\title{
Construction of Printing and Packaging Virtual Simulation Practice Platform and Research on Talent Training Mode Under the Background of New Engineering
}

\author{
Yonggang Yang ${ }^{1, *}$, Jianghao Liu ${ }^{1}$, Qiaozhuo $\mathrm{Gao}^{2}$ and Huaming Wang ${ }^{1}$ \\ ${ }^{1}$ School of Printing \& Packaging Engineering, Beijing Institute of Graphic Communication, Beijing, 102600, China \\ ${ }^{2}$ The Emerald City Branch of Beijing Primary School, Beijing, 102600, China \\ *Corresponding author. Email: yangyonggang@bigc.edu.cn
}

\begin{abstract}
Virtual simulation technology has been gradually applied in the main links of practical teaching and talent training of printing and packaging specialty. It will bring positive significance to "student-centered" autonomous learning and professional theory teaching. Firstly, this paper points out the necessity and main innovation of constructing virtual simulation experiment platform under the background of new engineering. Then, the reasonable and practical platform of the virtual simulation platform for lithographic offset printing process is introduced. Finally, the paper explores the positive role of the construction and application of virtual simulation experiment platform in promoting the development of autonomous learning, practical teaching reform and the cultivation of students' engineering practical ability from three aspects.
\end{abstract}

Keywords: new engineering; printing and packaging; virtual simulation practice platform; student-centered;

combination of virtual and real

\section{INTRODUCTION}

The construction and development of new engineering is proposed by Fudan consensus, TJU action and Beijing guidelines. With the educational goal of cultivating diversified and innovative excellent engineering talents, it has always carried out research and practice around five parts: the new concept of engineering education, the new structure of disciplines and specialties, the new mode of talent training, the new quality of education and teaching, classified development and the new system. In June 2017, the general office of the Ministry of Education issued the notice on recommending new engineering research and practice projects, and timely launched strategic measures for the construction of new engineering[1]. With the advances of major strategies as one belt and one road, Made in China 2025, the rapid development of new economy represented by new technology, new format, new mode and new industry has put forward higher requirements and challenges for the training of engineering professionals. In current universities, the primary goal and core of the construction of new engineering is that training high quality compound applied talents owning the abilities of strong interdisciplinary integration, higher engineering practical innovation, strong international vision.

\section{CONSTRUCTION OF VIRTUAL SIMULATION PRACTICE PLATFORM FOR PRINTING AND PACKAGING}

\subsection{The necessity of Constructing Virtual Simulation Experiment Platform}

In the practical teaching link of printing and packaging major, the production printing press, post press binding and finishing equipment and various packaging machinery, which are expensive, diverse, and them have long renewal cycle and high experimental cost, and the practical teaching environment is quite different from the actual production of enterprises, resulting in low student participation and difficult to ensure the effect of practical teaching, so it restricts the cultivation of compound applied talents. In addition, the experimental printing press, binding line, laminating machine and various packaging machinery are large in volume and occupy a large physical space. The ink and adhesive used for the experiment will also produce certain VOC emission and equipment cleaning wastewater, which is not friendly to the environment. Due to the limitations of experimental conditions, it is urgent to adopt virtual simulation practice technology and platform to replace real experimental equipment and some practice links. It can not only highly 
simulate the actual production environment, but also reduce the impact of insufficient environmental protection and safety factors in the traditional practice environment on students' physical health, and improve students' participation and sense of experience, and then it can also feed back the latest learning status in time, and improve greatly the learning effect[2].

In order to comprehensively improve students' innovative spirit and practical ability, share high-quality experimental teaching resources, and solve the disadvantages of high cost and poor reversibility of large-scale experiments and high-speed dynamic processes that are not conducive to monitoring and display, the school set up a printing and packaging virtual simulation experiment center in 2012.It sorted out and designed relevant course experiments, based on the principle of "combination of virtual and real, complement each other, being real but not virtual, and being as virtual as possible", and a part of the virtual simulation teaching resources are constructed. We have completed the upgrading of the virtual simulation software of offset printing (shots), gravure printing and flexographic printing in the virtual simulation experiment resources of printing process, built the teaching platform of printing and packaging virtual simulation experiment center, and developed the virtual simulation experiment resources of lithographic offset printing workshop[3]. At present, we are orderly promoting the development of virtual simulation experiment system in book binding workshop, post press processing workshop and the whole packaging process, and also optimizing the packaging box design system, the whole process flow of packaging visual processing system, packaging life cycle assessment system, etc. The construction of the platform helps students understand the real printing and packaging process from different dimensions, strengthen the communication and interaction between majors, and promote the cultivation of compound applied talents. At the same time, combined with the training scheme, the developed virtual simulation system platform is used to design and embed theoretical courses or courses with centralized practice links, such as printing professional practice, printing production and innovation practice, comprehensive training of packaging design, packaging and printing skills practice, etc.

\subsection{The Main Innovation of Constructing Virtual Simulation Experiment Platform}

By introducing the virtual simulation software into the practical teaching of printing and packaging talents training in the new engineering department, a near real printing and packaging production environment can be established, which can visualize the abstract printing process and printing faults, so that students can eliminate printing faults by themselves, carry out "on-line" printing production, and learn practical operation and fault analysis and troubleshooting by constantly trial and error, and then it stimulates students' enthusiasm and initiative in active learning. It can also digitize the huge packaging material production equipment and automatic filling and packaging line, which not only reduces the experimental workload and experimental cost, but also enhances students' practical ability and strengthens the effect of theoretical teaching. The design and construction of the virtual simulation practice platform will be comprehensively applied to a variety of advanced technologies such as information technology, VR technology, simulation technology, 3D modeling technology and artificial intelligence recognition technology, which can systematically train students' innovative thinking, and is expected to turn students from system users to system improvers and developers, so as to provide technical support for the continuous improvement and remote sharing of the practice platform in the future[4].

\section{CASE OF VIRTUAL SIMULATION PRACTICE PLATFORM FOR LITHOGRAPHIC OFFSET PRINTING PROCESS}

In order to meet the needs of the development of higher education and printing industry in China, with the goal of cultivating innovative and applied printing talents owning strong production and practice ability, and adhering to the experimental teaching concept of "student-centered, problem-oriented, discipline integration and innovative practice", the printing engineering specialty follows the principle of "combination of virtual and real, being real but not virtual", Taking Heidelberg offset printing production process and standard operation as the main experimental content, a virtual simulation system of lithographic offset printing process is independently developed by using 3D modeling, animation, sound effect, human-computer interaction and other technologies. The system includes operation process essentials such as safety inspection before startup, parameter setting, printing plate installation, ink volume adjustment, registration adjustment, preprinting, formal printing and equipment cleaning, which can effectively solve the problems of insufficient equipment, high cost and large consumption of experimental materials in the practical teaching of printing engineering specialty $[5,6]$.

\subsection{Rationality of Teaching Design of Virtual Simulation Experiment}

This experiment focuses on the production technology of Heidelberg offset press, and organically combines the water and ink balance principle in the course of Printing Principle and Technology, the printing color reproduction principle in the course of Color Science and Technology. The experiment is not only the operation of the equipment, but also allows students to better understand the specific application of these principles in the actual printing process. Based on the objectives and requirements of the practical course of Printing Practice, the experiment decomposes 
the teaching contents and knowledge points around the offset production line, covering 3 experimental principles and 17 theoretical and engineering training modules, and then form respective virtual simulation units. The whole practice training process is connected in series with these 17 modules. Personalized learning and assessment tasks can also be designed according to different competition training requirements or the positioning difference between theory and practice courses.

\subsection{The practicability of Virtual Simulation Practice Platform}

The experimental teaching project provides a learning mode and assessment mode. In the early stage, students can complete the operation of the equipment according to the program prompts through the learning mode, and can repeat the training for many times. The assessment mode carries out block assessment and overall assessment on the main equipment operation modules through random selection of multiple sets of different products, combined with the automatic scoring system of the software, It enables students to intuitively see the experimental results, effectively mobilizes students' enthusiasm and initiative in participating in experimental teaching, stimulates students' learning interest and potential, and promotes the universal application of inquiry teaching methods. The simulated printed matter randomly selected in the assessment mode also sets the difficulty of ink volume adjustment for students. Students need to adjust and set it in combination with the theoretical knowledge learned and the actual production effect, which effectively improves students' comprehensive ability to solve complex problems, cultivates students' thinking mode of independent problem analysis, so it reflects the high-level and challenge of the course[7]

\section{EXPERIMENTAL TEACHING PROCESS}

The experiment lasts for 2 days. The experimental teaching process is an engineering training mode based on network and students' autonomous learning. The specific process is as follows.

Before the course, students learn and prepare independently for the experimental contents through the study and reference of theoretical knowledge and the summary of problems in the practice of real printing equipment.

In class, students use network resources to study independently (centralized or decentralized) according to groups and tasks. Firstly, through the virtual experiment, learn the safety precautions and complete experimental process flow in the factory environment, and master the relevant operating procedures of offset printing press; Then enter the learning mode in the virtual experiment. Students need to complete the tasks of each stage before they can enter the next stage of learning. This learning mode can be studied repeatedly until students master it; Then enter the assessment mode, students need to complete the assessment of 9 modules to test the learning effect of the virtual experiment. Teachers only play the role of guidance, clarification and promotion.

Finally, after students submit the assessment results, teachers can analyze the assessment results and give guiding opinions through the teaching network platform.

\section{EXPLORATION ON THE TRAINING MODE OF INNOVATIVE TALENTS IN PRINTING ENGINEERING}

\subsection{Build a Student-centered Autonomous Engineering Training Mode Based on Virtual Simulation Environment}

With the construction of new engineering, schools pay more attention to practical teaching and continuously purchase advanced processing equipment related to printing. However, the contradiction of shortening the training operation time caused by the increase of training content is becoming more and more prominent. Therefore, it is of great practical significance to explore the open teaching mode based on network, break through the limitations of time and space, and realize the engineering training practice of combining online and offline based on student-centered and autonomous learning. After teachers assign learning tasks, students use network resources to study independently (centralized or decentralized) by individuals or groups [8]. Through the virtual experiment, students can learn the safety precautions and complete experimental process flow in the factory environment, and further master the relevant operating procedures of offset printing press.

\subsection{Carry Out a New Paradigm of Practical Teaching Guided by Projects and Aimed at Undergraduate Teaching Reform and Innovation}

The traditional teaching is usually embodied in engineering training, which is the learning and equipment operation. The project led teaching mode is guided by the project and technology. In the process of completing the project experiment, students need to constantly solve the faults in the experiment process in order to finally complete the experimental requirements. This teaching method helps to stimulate learning interest, tap students' innovative potential, cultivate active exploration spirit and learning enthusiasm, and improve students' engineering literacy. 


\subsection{Cultivate Students' Engineering Practice and Innovation Ability through "Combination of Virtual and Real" Learning and Breakthrough Assessment}

As an indispensable teaching subject of engineering training, offset press practice is widely used in industrial production. Due to the large volume and heavy weight of these equipment, and high waste rate of consumables in the operation process, it is very necessary to build a virtual project and realize the teaching mode of combination of virtual and real[9]. Through the virtual simulation system for the simulation operation of the actual offset press, students can master the operation of the offset press faster in the environment with strong sense of reality and presence. Through online virtual operation, they can master the operation method of offset press, and have more time for practical training in class, which greatly improves the training efficiency. Members of each group can basically directly operate all links of offset press, and achieve better engineering training effect through the combination of virtual and real.

\section{CONCLUSION}

The necessity, practicability and main innovation of constructing virtual simulation experiment platform under the background of new engineering were introduced in this paper. Then, it gave experimental teaching methods and steps of the virtual simulation platform for lithographic offset printing process. Finally, the paper explores the positive role of the construction and application of virtual simulation experiment platform in promoting the development of autonomous learning, practical teaching reform and the cultivation of students' engineering practical ability from three aspects sheet. This platform will also certainly promote the green, intelligent and integrated printing technology.

\section{ACKNOWLEDGMENT}

This thesis is supported by the undergraduate teaching reform and innovation project of Beijing Higher Education in 2019 (Project No.: 22150120018).

\section{REFERENCES}

[1]G.M.Zhang, YG.Yang, X.L. Song, Discussion and Practice on the construction of comprehensive training platform for printing and packaging engineering under the background of new engineering $[\mathrm{J}]$, Packaging Engineering, 2019(12):34-37.

[2]G.Y. Wu, X.Z.Li, X.Wang. Practice and exploration of virtual simulation teaching of printing engineering specialty under the background of new engineering[J], Education Modernization, 2018(6):173-175.

[3]J. H. Guo, J.F.Cui, B.P.Yang, Construction of virtual simulation experiment project of virtual reality combination under the background of new engineering[J], Experimental Technology and Management, 2019(8):119-123.

[4]C.X. Zhang, W.Li, X.L. Zhu. Application of virtual simulation system in practical teaching reform of printing engineering specialty[J], Hunan Packaging, 2017(12):137-139.

[5]G. Li, H.Y. Song, B.Q. Sun. Construction and practice of national virtual simulation experiment teaching center for packaging engineering $[\mathrm{J}]$, Packaging Engineering, 2019(12): 47-51.

[6]J.H. Wang, H. Fu, Z.W. S. Construction of virtual simulation practice teaching and innovation platform of packaging design under the background of new engineering[J], Hunan Packaging, 2018(2):114-117.

[7]B.J.Du, W.B.Lv, L.Lin. Simulation of printing system based on Virtual Prototype Technology[J], Information Technology, 2015(7): 147-151.

[8]Z.J. Zhang, X.P. Zhao, Y.Z. Chen. Constructing virtual simulation experiment teaching platform and cultivating innovative and applied talents[J], Printing Field, 2014(3):59-61.

[9]Y.Liu, W.Y. Tang. Application of virtual simulation technology in printing Teaching[J], Print Today, 2011(5): 71-73. 